\title{
LETTER
}

\section{Early aqueous alteration process in the QUE97990 and Y791198 CM carbonaceous chondrites}

\author{
Makoto MAEDA, Kazushige TomeOKA and Yusuke SETO \\ Department of Earth and Planetary Sciences, Faculty of Science, \\ Kobe University, Nada, Kobe 657-8501, Japan
}

\begin{abstract}
Queen Alexandra Range 97990 (QUE97990) and Yamato 791198 (Y791198) are among the least aqueously altered CM carbonaceous chondrites known to date. Our mineralogical and petrographic study reveals that chondrule mesostases in QUE97990 contain dense arrays of parallel, thin lath-shaped crystallites of diopside. The diopside crystallites are primary quenched products formed during chondrule formation. Thus their presence suggests that QUE97990 preserves a very early state of aqueous alteration. On the other hand, chondrule mesostases in Y791198 consist largely of serpentine without such quenched crystallites. In Y791198, quenched crystallites have probably been replaced by serpentine due to a higher degree of alteration than in QUE97990. Our study also reveals that chondrules in both QUE97990 and Y791198 show topographic depressions on their surfaces. The texture and mineralogy of the depressions suggest that they formed by replacing opaque nodules in their host chondrules during aqueous alteration. These imply that, in spite of the evidence of incipient alteration in the chondrule interiors, there was considerable alteration reaction between the chondrule margins and their surrounding rims in QUE97990. We suggest that the aqueous alteration in both meteorites occurred after the chondrules acquired their own rims on the meteorite parent bodies.
\end{abstract}

Keywords: Carbonaceous chondrites, CM chondrites, Aqueous alteration, QUE97990, Chondrule rims, Opaque nodule

\section{INTRODUCTION}

Aqueous alteration is a very important process that occurred widely in the early solar system. CM carbonaceous chondrites contain abundant hydrous phyllosilicates, most of which formed by aqueous alteration of anhydrous silicates such as olivine and pyroxene. A number of previous workers (e.g., Tomeoka and Buseck, 1985; Metzler et al., 1992; Browning et al., 1996; Bischoff, 1998; Hanowski and Brearley, 2001; Jones and Brearley, 2006; Chizmadia and Brearley, 2008) discussed the mechanism, condition and location of aqueous alteration in the CM chondrites. However, it is still controversial whether the aqueous alteration occurred in the solar nebula (e.g., Metzler et al., 1992; Bischoff, 1998) or on the meteorite parent bodies (e.g., Browning et al., 1996; Chizmadia and Brearley, 2008). Because progressive aqueous alteration on the parent bodies probably overwrote the earlier alteration history, it is desirable to investigate meteorites that have expe-

doi:10.2465/jmps.081022a

M. Maeda, 055s460s@stu.kobe-u.ac.jp Corresponding author

K. Tomeoka, tomeoka@kobe-u.ac.jp rienced aqueous alteration as little as possible to unravel the earliest alteration process.

The Yamato 791198 (Y791198) CM chondrite has been described by Metzler et al. (1992) as "a primary accretionary rock, obviously unaltered by secondary parent body processes such as aqueous alteration or brecciation." Since then, Y791198 has been recognized as the most primitive CM chondrite. Recently, however, Rubin et al. (2007) studied many CM chondrites, including Y791198, and estimated that the degree of aqueous alteration of a more recently described CM chondrite-Queen Alexandra Range 97990 (QUE97990) is lower than that of Y791198 based on Fe-Ni metal abundance. If this is the case, there is a possibility that QUE97990 gives us new insight into the early aqueous alteration process of the $\mathrm{CM}$ chondrites. We here present the results of our mineralogical and petrographic study of chondrules and their rims in the QUE97990 and Y791198 CM chondrites. Our goal was to examine relative degree of aqueous alteration of these two meteorites and to unravel the early aqueous alteration history of the $\mathrm{CM}$ chondrites. 


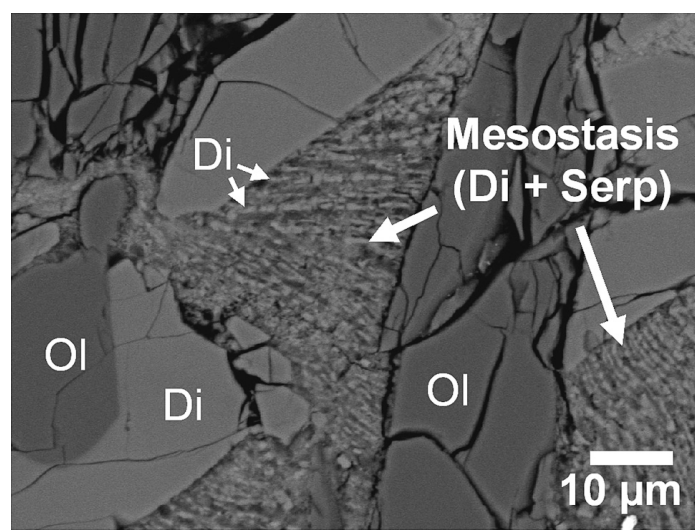

Figure 1. BSE image of a chondrule interior, including mesostasis, in QUE97990. The mesostasis contains dense arrays of parallel, thin lath-shaped crystallites of diopside (Di) embedded in $\mathrm{Mg}-\mathrm{Fe}$ serpentine (Serp). Phenocrysts are olivine (Ol) and diopside. This is an image of the smaller boxed area in Figure 2a.

\section{MATERIALS AND METHODS}

The samples used for this study are two polished thin sections of QUE97990 and Y791198. The thin section of QUE97990 was provided by NASA Johnson Space Center and that of Y791198 by the National Institute of Polar Research. They were studied using a scanning electron microscope (SEM) (JEOL JSM-6480LVII) equipped with an energy-dispersive X-ray spectrometer (EDS) (JEOL EX-2300BU) and an electron probe microanalyzer (JEOL JXA-8900) equipped with wavelength-dispersive X-ray spectrometers (WDS). For most SEM observations, we used backscattered electron (BSE) imaging. EDS analyses were obtained at $15 \mathrm{kV}$ and $0.6 \mathrm{nA}$, and WDS at $15 \mathrm{kV}$ and $12 \mathrm{nA}$. Data corrections were made by the ZAF method for EDS analyses, and the Bence-Albee method for WDS analyses. Well-characterized natural and synthetic minerals were used as chemical standards.

\section{RESULTS}

\section{Chondrules and rims}

Chondrules in both QUE97990 and Y791198 mainly consist of phenocrysts of olivine and enstatite, with minor amounts of diopside, and mesostasis. Most chondrules contain opaque nodules $(10-150 \mu \mathrm{m}$ in diameter) that consist of $\mathrm{Fe}-\mathrm{Ni}$ metal (both kamacite and taenite) and troilite, which have been commonly partially replaced by tochilinite and cronstedtite. Phenocrysts of olivine and enstatite show no evidence of replacement by phyllosilicate, although their mesostases have been affected by aqueous alteration as described below. In chondrules of most other CM chondrites, phenocrysts of olivine and en-
Table 1. EDS analyses of chondrule mesostases

\begin{tabular}{|c|c|c|}
\hline \multirow[b]{3}{*}{ No. of analyses } & \multicolumn{2}{|c|}{ Chondrule mesostases } \\
\hline & QUE97990 & Y791198 \\
\hline & 35 & 40 \\
\hline $\mathrm{SiO}_{2}(\mathrm{wt} \%)$ & $22.1( \pm 4.6)^{*}$ & $27.2( \pm 3.2)$ \\
\hline $\mathrm{TiO}_{2}$ & $0.28( \pm 0.29)$ & $0.20( \pm 0.07)$ \\
\hline $\mathrm{Al}_{2} \mathrm{O}_{3}$ & $5.96( \pm 2.19)$ & $5.31( \pm 2.05)$ \\
\hline $\mathrm{Cr}_{2} \mathrm{O}_{3}$ & $0.36( \pm 0.21)$ & $0.76( \pm 0.95)$ \\
\hline $\mathrm{FeO}$ & $34.9( \pm 8.1)$ & $23.9( \pm 4.6)$ \\
\hline $\mathrm{NiO}$ & $0.60( \pm 0.42)$ & $0.78( \pm 0.84)$ \\
\hline $\mathrm{MnO}$ & $0.21( \pm 0.15)$ & $0.20( \pm 0.14)$ \\
\hline $\mathrm{MgO}$ & $11.7 \quad( \pm 3.7 \quad)$ & $20.2( \pm 4.0)$ \\
\hline $\mathrm{CaO}$ & $1.35( \pm 1.71)$ & $0.34( \pm 0.58)$ \\
\hline $\mathrm{Na}_{2} \mathrm{O}$ & $0.35( \pm 0.65)$ & $0.17( \pm 0.14)$ \\
\hline $\mathrm{S}$ & $1.51( \pm 0.95)$ & $1.22( \pm 1.24)$ \\
\hline Total & 79.3 & 80.3 \\
\hline
\end{tabular}

The analyses were performed by using a defocused beam $(\sim 5$ $\mu \mathrm{m}$ in diameter).

$\mathrm{Fe}$ contents are calculated as $\mathrm{FeO}$, but part of $\mathrm{Fe}$ is probably contributed from $\mathrm{Fe}$ sulfide.

* Standard deviation.

statite have been partially replaced by phyllosilicates (e.g., Hanowski and Brearley, 2001; Rubin et al., 2007). Thus the observation suggests that the degree of aqueous alteration of both meteorites is low relative to other $\mathrm{CM}$ chondrites.

Chondrules in both meteorites are surrounded by fine-grained rims that are typically 10 to $100 \mu \mathrm{m}$ thick. The rims consist mainly of $\mathrm{Mg}-\mathrm{Fe}$ serpentine, with minor amounts of tochilinite and fine grains $(<5 \mu \mathrm{m}$ in size $)$ of olivine, pyroxene, $\mathrm{Ca}-$ carbonate, troilite, pentlandite, and Fe-Ni metal. Previous workers (e.g., Metzler et al., 1992; Hanowski and Brearley, 2001) reported that Fe-Ni metal is rare in rims of $\mathrm{CM}$ chondrites because of its high susceptibly to aqueous alteration. However, Fe-Ni metal is common in the rims of QUE97990. Fe-Ni metal also occurs in the rims of Y791198 but in lower abundance. Anhydrous silicates in the rims of QUE97990 include forsteritic olivine ( $\mathrm{Fo}_{90-100} ; \sim 60 \%$ in abundance), enstatite $(\sim 30 \%)$, and diopside $(\sim 10 \%)$, whereas anhydrous silicates in the rims of Y791198 include forsteritic olivine $(\sim 90 \%)$ and diopside $(\sim 10 \%)$, but no enstatite. The lower abundance of $\mathrm{Fe}-\mathrm{Ni}$ metal and the absence of enstatite in the Y791198 rims suggest that Y791198 has experienced a higher degree of aqueous alteration than QUE97990.

\section{Chondrule mesostases}

Chondrule mesostases in both QUE97990 and Y791198 have been largely altered to $\mathrm{Mg}-\mathrm{Fe}$ serpentine. However, their microtextures show distinct differences. $9(\sim 41 \%)$ of the 22 chondrule mesostases in QUE97990 studied 

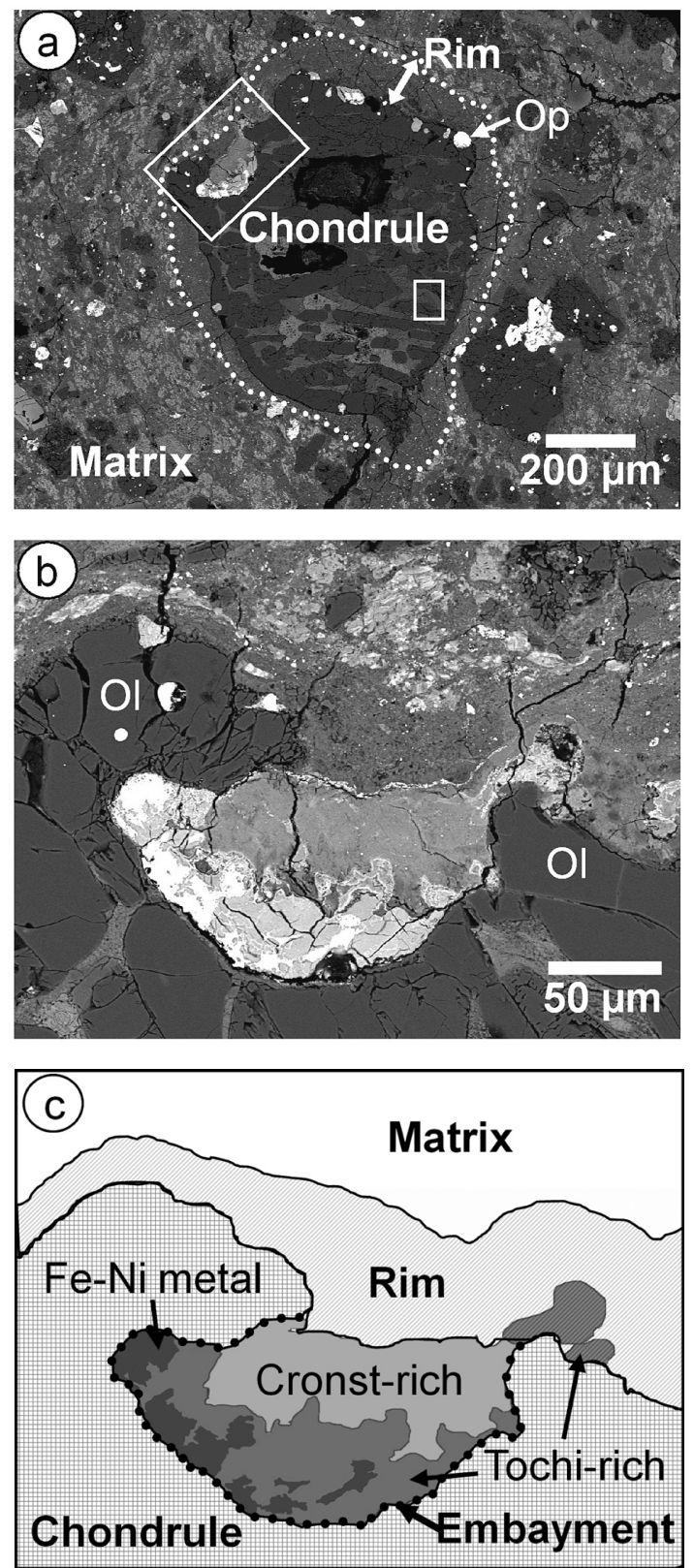

Figure 2. (a) BSE image of a chondrule surrounded by a rim in QUE97990. The chondrule consists largely of olivine (Ol) phenocrysts and mesostasis. Note that opaque nodules (Op) are contained near the chondrule surface. (b) Image of the larger boxed area in (a), showing an embayment on the chondrule surface. (c) Illustration of (b) showing three zones, (1) Fe-Ni metal, (2) tochilinite (Tochi)-rich, and (3) cronstedtite (Cronst)-rich, in the embayment (indicated by a dotted line).

contain dense arrays of parallel, thin lath-shaped crystallites $(\sim 1 \mu \mathrm{m}$ in width) of diopside (Fig. 1$)$, which are primary quenched products formed during chondrule formation. On the other hand, no such quenched crystallites were found in any of the 25 chondrule mesostases in Y791198 studied. The focused-beam chemical analysis indicates that the serpentine in the QUE97990 mesostases
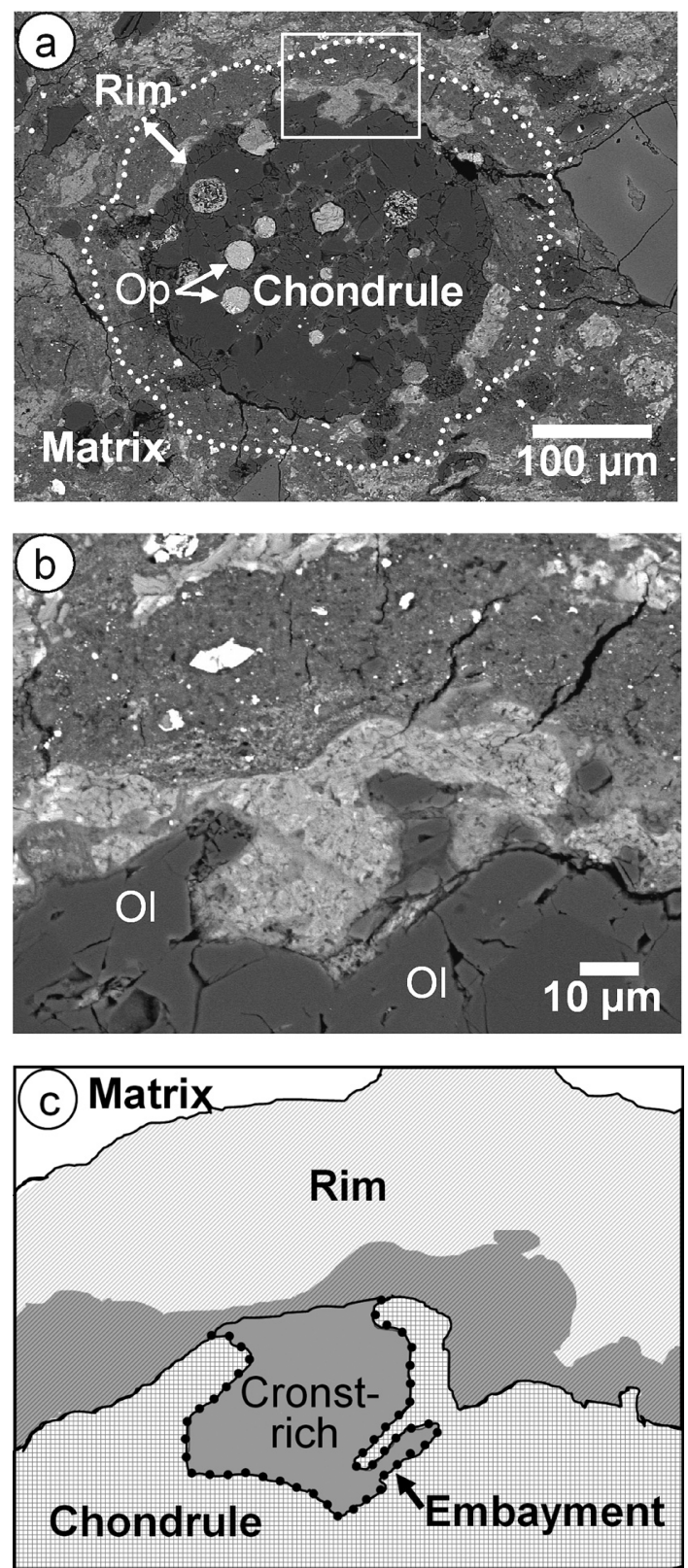

Figure 3. (a) BSE image of a chondrule surrounded by a rim in QUE97990. The chondrule consists largely of olivine (Ol) phenocrysts and mesostasis, with opaque nodules (Op). (b) Image of boxed area in (a), showing an embayment on the chondrule surface. (c) Illustration of (b) showing the cronstedtite (Cronst)-rich material not only fills the embayment (indicated by a dotted line) but also extends to the outside of the embayment.

is more heterogeneous than that in the Y791198 mesostases, which is reflected in the relatively high standard deviation of $\mathrm{FeO}$ contents in the analyses of the former (Table $1)$.

\section{Chondrule margins}

$18(\sim 72 \%)$ of the 25 chondrules in QUE97990 studied 
Table 2. EDS analyses of materials in the chondrule embayments and rims

\begin{tabular}{|c|c|c|c|c|c|}
\hline \multirow[b]{4}{*}{ No. of analyses } & \multicolumn{3}{|c|}{ QUE97990 } & \multicolumn{2}{|c|}{ Y791198 } \\
\hline & \multicolumn{2}{|c|}{ Embayments } & \multirow{2}{*}{$\frac{\text { Rims }}{\text { Mg-Fe serpentine-rich }}$} & \multirow{2}{*}{$\frac{\text { Embayments }}{\text { Mg-Fe serpentine-rich }}$} & \multirow{2}{*}{$\frac{\text { Rims }}{\text { Mg-Fe serpentine-rich }}$} \\
\hline & Tochilinite-rich & Cronstedtite-rich & & & \\
\hline & 20 & 21 & 40 & 35 & 40 \\
\hline $\mathrm{SiO}_{2}(\mathrm{wt} \%)$ & $3.47( \pm 0.99)^{*}$ & $20.3 \quad( \pm 3.3)$ & $24.3( \pm 1.9)$ & $26.8 \quad( \pm 1.2)$ & $28.4( \pm 1.2)$ \\
\hline $\mathrm{TiO}_{2}$ & $0.14( \pm 0.05)$ & $0.11( \pm 0.09)$ & $0.11( \pm 0.09)$ & $0.2( \pm 0.10)$ & $0.13( \pm 0.10)$ \\
\hline $\mathrm{Al}_{2} \mathrm{O}_{3}$ & $0.55( \pm 0.14)$ & $3.98( \pm 0.87)$ & $2.87( \pm 0.48)$ & $2.58( \pm 0.61)$ & $2.21( \pm 0.22)$ \\
\hline $\mathrm{Cr}_{2} \mathrm{O}_{3}$ & $1.78( \pm 1.09)$ & $0.61( \pm 0.92)$ & $0.44( \pm 0.17)$ & $0.53( \pm 0.24)$ & $0.48( \pm 0.24)$ \\
\hline $\mathrm{FeO}$ & $46.1 \quad( \pm 2.9 \quad)$ & $40.6 \quad( \pm 11.4)$ & $25.2( \pm 1.7)$ & $29.0 \quad( \pm 2.5 \quad)$ & $27.78( \pm 1.9)$ \\
\hline $\mathrm{NiO}$ & $11.1 \quad( \pm 1.7)$ & $2.09( \pm 1.62)$ & $2.59( \pm 0.54)$ & $2.20( \pm 0.65)$ & $2.46( \pm 0.44)$ \\
\hline $\mathrm{MnO}$ & $1.15( \pm 0.33)$ & $1.00( \pm 0.39)$ & $0.18( \pm 0.21)$ & $0.86( \pm 0.13)$ & $0.84( \pm 0.21)$ \\
\hline $\mathrm{MgO}$ & $3.83( \pm 0.47)$ & $8.91( \pm 2.93)$ & $14.4 \quad( \pm 1.8)$ & $14.4( \pm 1.6)$ & $15.6( \pm 1.7)$ \\
\hline $\mathrm{CaO}$ & $0.73( \pm 0.17)$ & $0.50( \pm 0.50)$ & $1.03( \pm 0.28)$ & $0.65( \pm 0.11)$ & $0.31( \pm 0.12)$ \\
\hline $\mathrm{Na}_{2} \mathrm{O}$ & $0.13( \pm 0.07)$ & $0.36( \pm 0.23)$ & $0.16( \pm 0.12)$ & $0.21( \pm 0.10)$ & $0.19( \pm 0.12)$ \\
\hline $\mathrm{S}$ & $15.6( \pm 1.1)$ & $2.92( \pm 1.48)$ & $4.08( \pm 0.70)$ & $3.49( \pm 0.88)$ & $3.53( \pm 0.73)$ \\
\hline Total & 84.6 & 81.4 & 75.4 & 80.9 & 81.9 \\
\hline
\end{tabular}

The analyses were performed by using a defocused beam $(\sim 5 \mu \mathrm{m}$ in diameter).

$\mathrm{Fe}$ contents are calculated as $\mathrm{FeO}$, but part of $\mathrm{Fe}$ is probably contributed from Fe sulfide.

*Standard deviation.

show topographic depressions on their surfaces (Figs. $2 a-2 c$ and $3 a-3 c)$. We refer to these depressions as embayments. The size and shape of the embayments are comparable to those of opaque nodules contained within the chondrules (see Figs. 2a and $3 \mathrm{a}$ for example). The inside of the embayments commonly consists of one to all of three materials: (1) Fe-Ni metal, (2) tochilinite-rich, and (3) cronstedtite-rich (Figs. 2b, 2c, 3b, 3c, and Table 2 ); the identification of materials (2) and (3) is based on their compositional similarities to tochilinite and cronstedtite, respectively (see Table 2 in Tomeoka and Buseck (1985)). The tochilinite-rich material is distinctly richer in $\mathrm{Fe}, \mathrm{Ni}$ and $\mathrm{S}$, and the cronstedtite-rich material is richer in Fe than the rims (Table 2); thus these materials appear brighter than the rims in BSE images. In many embayments, Fe-Ni metal commonly occurs at the bottom, and the tochilinite-rich material and the cronstedtite-rich material occur toward the outside, thus exhibiting a zonal texture (Figs. $2 b$ and $2 c$ ). Figures $3 b$ and $3 c$ show that the cronstedtite-rich material occurs in not only the inside but also the outside of an embayment.

$16(\sim 64 \%)$ of the 25 chondrules in Y791198 studied also show embayments on their surfaces (Figs. 4a-4c). However, $\mathrm{Fe}-\mathrm{Ni}$ metal, tochilinite and cronstedtite are rare, and the inside of the embayments is largely composed of the $\mathrm{Mg}-\mathrm{Fe}$ serpentine-rich material that is indistinguishable from the surrounding rims (Table 2).

\section{DISCCUSION}

Our study revealed that the chondrule mesostases in
QUE97990 contain quenched crystallites of diopside, but the chondrule mesostases in Y791198 contain no such crystallites. Quenched crystallites of diopside are commonly observed in chondrule mesostases in anhydrous type 3 chondrites (e.g., Jones and Scott, 1989; Jones and Danielson, 1997), but have not been reported from any CM chondrites. Quenched crystallites in most CM chondrites have probably been replaced by phyllosilicates due to higher degrees of aqueous alteration than that in QUE97990. Thus the presence of quenched crystallites in the mesostases suggests that QUE97990 preserves a very early state of aqueous alteration, and supports the conclusion of Rubin et al. (2007) that the degree of aqueous alteration in QUE97990 is lower than that in Y791198.

However, our study also revealed evidence suggesting that considerable alteration reaction occurred along the margins of chondrules in QUE97990. The texture and mineralogy of the embayments on the chondrule surfaces suggest that they were formed by replacing opaque nodules, which were located near the surfaces of their host chondrules, during aqueous alteration. The $\mathrm{Fe}-\mathrm{Ni}$ metal at the bottom of the embayments is probably an unaltered residue of opaque nodules, and the tochilinite-rich and cronstedtite-rich materials are secondary products formed by replacing $\mathrm{Fe}-\mathrm{Ni}$ metal and/or troilite in opaque nodules (Figs. 2b, 2c, 3b, and 3c). In Y791198, the inside of the embayments has probably been more extensively altered than in QUE97990, and thus has been largely replaced by the $\mathrm{Mg}$-Fe serpentine-rich material (Figs. $4 \mathrm{~b}$ and $4 \mathrm{c}$ )

The texture of the chondrule embayments and rims in both QUE97990 and Y791198 suggests that the altera- 

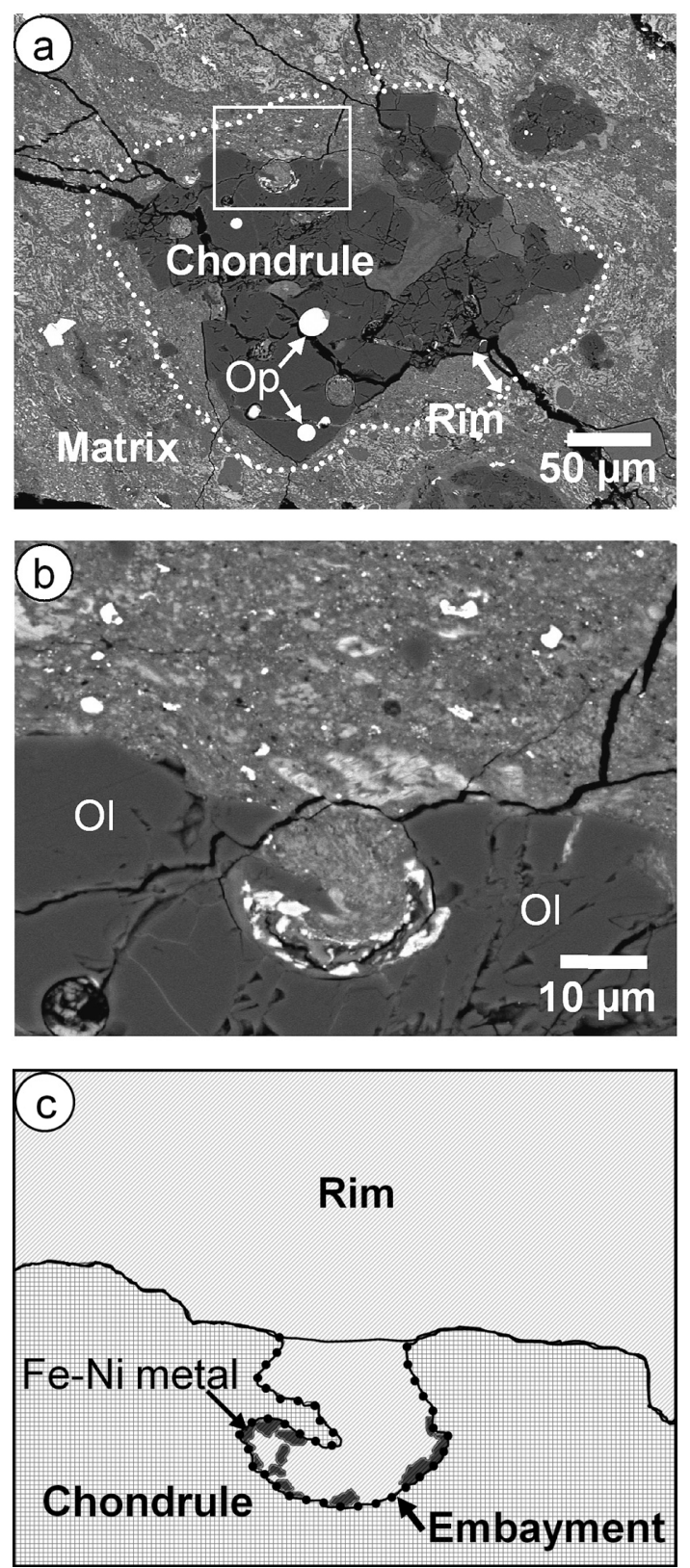

Figure 4. (a) BSE image of a chondrule surrounded by a rim in Y791198. The chondrule consists largely of olivine (Ol) phenocrysts and mesostasis, with opaque nodules (Op). (b) Image of boxed area in (a), showing an embayment on the chondrule surface. (c) Illustration of (b) showing that the embayment (indicated by a dotted line) is filled with the material that is indistinguishable from the rim. Minor amounts of Fe-Ni metal grains occur along the edge of the embayment.

tion reaction took place after the chondrules acquired their own rims. The chondrule margins have probably been involved in extensive dissolution, and transportation and deposition of dissolved ions in the rims. These reaction and process most likely proceeded with the presence of aqueous solutions. Therefore we suggest that the aqueous alteration in both meteorites occurred on their parent bod- ies.

\section{ACKNOWLEDGMENTS}

We thank NASA Johnson Space Center for providing a QUE97990 sample and the National Institute of Polar Research for providing a Y791198 sample. We also thank two anonymous reviewers for helpful comments. Electron microprobe analysis was performed at the Venture Business Laboratory, Kobe University. This work was supported by the Grant-in-Aid for Scientific Research (No. 20340150). Y.S. is also supported by Japan Society for the Promotion of Science research fellowship.

\section{REFERENCES}

Bischoff, A. (1998) Aqueous alteration of carbonaceous chondrites: Evidence for preaccretionary alteration-A review. Meteoritics \& Planetary Science, 33, 1113-1122.

Browning, L.B., McSween, H.Y.J. and Zolensky, M.E. (1996) Correlated alteration effects in CM carbonaceous chondrites. Geochimica et Cosmochimica Acta, 60, 2621-2633.

Chizmadia, L.J. and Brearley, A.J. (2008) Mineralogy, aqueous alteration, and primitive textural characteristics of fine-grained rims in the Y-791198 CM2 carbonaceous chondrite: TEM observations and comparison to ALHA81002. Geochimica et Cosmochimica Acta, 72, 602-625.

Hanowski, N.P. and Brearley, A.J. (2001) Aqueous alteration of chondrules in the CM carbonaceous chondrite, Allan Hills 81002: Implications for parent body alteration. Geochimica et Cosmochimica Acta, 65, 495-518.

Jones, C.L. and Brearley, A.J. (2006) Experimental aqueous alteration of the Allende meteorite under oxidizing conditions: Constraints on asteroidal alteration. Geochimica et Cosmochimica Acta, 70, 1040-1058.

Jones, R.H. and Scott, E.R.D. (1989) Petrology and thermal history of type IA chondrules in Semarkona (LL3.0) chondrite. Proceeding of the 19th Lunar and Planetary Science Conference, 523-536.

Jones, R.H. and Danielson, L.R. (1997) A chondrule origin for dusty relict olivine in unequilibrated chondrites. Meteoritics \& Planetary Science, 32, 753-760.

Metzler, K., Bischoff, A. and Stöffler, D. (1992) Accretionary dust mantles in CM chondrites: Evidence for solar nebula process. Geochimica et Cosmochimica Acta, 56, 2823-2897.

Rubin, A.E., Trigo-Rodrígez, J.M., Huuber, H. and Wasson, J.T. (2007) Progressive aqueous alteration of CM carbonaceous chondrites. Geochimica et Cosmochimica Acta, 71, 23612382.

Tomeoka, K. and Buseck, P. R. (1985) Indicator of aqueous alteration in $\mathrm{CM}$ carbonaceous chondrites: Microtextures of a layered mineral containing $\mathrm{Fe}, \mathrm{S}, \mathrm{O}$ and Ni. Geochimica et Cosmochimica Acta, 52, 2149-2163.

\footnotetext{
Manuscript received October 22, 2008

Manuscript accepted December 9, 2008

Published online February 26, 2009

Manuscript handled by Koichiro Fujimoto
} 